\title{
Personal And Work-Related Predictors Of Organizational Commitment And Life Satisfaction Of Slovak Women In Higher Education
}

\author{
Joanne Brandt, Minnesota State University, Mankato ${ }^{1}$
}

Rosemary Krawczyk, (Email: rosemary.krawczyk@mnsu.edu), Minnesota State University, Mankato Jon Kalinowski, (Email: jon.kalinowski@mnsu.edu), Minnesota State University, Mankato

\begin{abstract}
Two samples of Slovak women in higher education were surveyed in order to determine the extent to which organizational commitment and life satisfaction are related to personal and work-related attributes. Organizational commitment was found to be related to the work-related attributes of role conflict and role ambiguity. These work-related attributes were not correlated with life satisfaction. A positive relationship was found between Professional Role Orientation and life satisfaction in one of the samples surveyed. Organizational Role Orientation did not correlate significantly with either organizational commitment or life satisfaction. The personal attribute of locus of control did not correlate with life satisfaction but there was a significant correlation between locus of control and organizational commitment in the 1996 Slovak sample. Results are discussed in comparison to findings from similar surveys of U.S. women in higher education and with respect to changes in higher education in post-communist Central and Eastern European countries.
\end{abstract}

\section{INTRODUCTION}

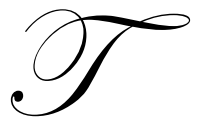

he relationship between the personal attributes of women and their job satisfaction and commitment has been studied in women holding administrative positions in higher education as well as outside the academic arena. This research has shown that the job satisfaction of women in higher education is significantly affected by their interpersonal style in the work environment (Steward et al., 1995). Murphy, Owen, and Gable (1988) found that organizational commitment was related to role orientation of women academic administrators. Additionally, the personal attribute of locus of control was found to moderate the influence of workrelated attributes on job satisfaction and organizational commitment (Loscocco \& Roschelle, 1991). Ward (1995) indicated that role conflict and ambiguity are related to job satisfaction and turnover. Blackhurst, Brandt, and Kalinowski (1998) examined the extent to which personal attributes are related to the life satisfaction of U.S. women in administrative positions in higher education. They found that organizational commitment was related to role ambiguity, role conflict and organizational role orientation. Life satisfaction was found to be negatively related to role ambiguity, role conflict and professional role orientation and positively related to internal locus of control. The purpose of the present study is to extend the findings on personal and work-related attributes of women in higher education and organizational commitment and life satisfaction to a sample of Slovak women in higher education. Past research has focused on samples derived from women in the U.S. Based on that earlier research, we expect that we will find (1) a significant positive relationship between organizational commitment and the personal attribute of organizational role orientation; (2) a significant negative relationship between professional role orientation and life satisfaction; (3) a significant negative relationship between role ambiguity and both

\footnotetext{
${ }^{1}$ This research was initiated by Dr. Joanne E. Brandt who passed away in August, 2007. This work is dedicated to her memory.
} 
organizational commitment and life satisfaction; (4) a significant negative relationship between role conflict and both organizational commitment and life satisfaction; and (5) a significant positive relationship between life satisfaction and internal locus of control.

\section{METHOD}

\section{Participants}

Two samples of women working in higher education at the University of Bratislava, Slovak Republic were recruited for this study with the help of Dr. Michal Liday and Dr. Helena Sajgalikova, both faculty members at that university. The first sample, drawn in 1996, consisted of 55 women whose mean age was 37.73 years. The mean number of years that these women had been employed in higher education was 12.79 . The second sample was drawn in 2006. This sample was comprised of 36 women with a mean age of 46.57 years, who had worked in higher education for an average of 19.01 years.

\section{Procedures And Instrumentation}

Research data were collected using a questionnaire, Women in Higher Education, which was translated into Slovakian for the purposes of this study. Included in this questionnaire were subscales assessing Role Orientation, Role Conflict and Ambiguity, Organizational Commitment, Life Satisfaction, Social Orientation (Rotter InternalExternal Locus of Control Scale), Personal Orientation, and sample demographics.

\section{Role Orientation}

This scale measures the degree to which respondents are oriented toward their institutions and/or their professional areas. Those with an Organizational Role Orientation place a high value on their academic responsibilities within their institutions and identify strongly with their academic units. Respondents with a Professional Role Orientation identify most strongly with their larger professional affiliations outside of the university. This scale consists of 10 Likert-type items with $1=$ strongly disagree and $4=$ strongly agree. The reliability estimate for this scale is .88 (Murphy et al., 1988).

\section{Role Conflict And Ambiguity}

This scale measures the extent to which respondents report experiencing a) conflict between the various role expectations in the workplace and the demands placed on their time, and b) ambiguity about performance expectations. Making up this scale are seven-point, Likert-type items ranging from 1= Definitely NOT TRUE of my job to $7=$ Definitely True of my job. Reliability estimates for this scale range from .80 to .82 (Murphy et al., 1988).

\section{Organizational Commitment}

This scale assesses respondents' degree of satisfaction with their work setting, compatibility with organizational values, and commitment to the organization. Participants respond on a five-point, Likert-type scale to statements like, I find that my values and the university's values are very similar. The reported reliability estimates for this scale have ranged from .82 to .93 (Murphy et al., 1988).

\section{Rotter Internal-External Locus Of Control Scale}

The 26 item Rotter Scale measures the extent to which respondents attribute life events to either internal or external causes. The scale is scored toward externality, with higher scores indicating a more external locus of control. The Rotter Scale has been found to have moderate to high concurrent validity (Goodman, 1987; Zerega, 1976). Reliability estimates range from .60 to .89 (Goodman, 1987; Rotter, 1966). 
Life Satisfaction Index-A (LSI-A)

The LSI-A measures five facets of life satisfaction: a) zest vs. apathy, b) resolution and fortitude, c) congruence between desired and achieved goals, d) positive self concept, and e) mood tone. The version of the LSIA used in this study consists of 20, five-point Likert-type items with $1=$ strongly disagree and 5= strongly agree. The LSI-A correlates moderately with other measures of life satisfaction ( Neugarten et al., 1961). The reliability estimate is .89 (Blackhurst, Brandt \& Kalinowski, 1998).

\section{RESULTS}

\section{SAMPLE 1 (1996)}

\section{Personal Attributes}

Means, ranges and standard deviations for all measured attributes may be found in Table 1. In this sample, Organizational Role Orientation scores ranged from 8 to 19, with a mean of 12.72. The mean score for Professional Role Orientation was 14.73, with scores ranging from 5 to 46. Scores on the Rotter Internal-External Locus of Control Scale ranged from 5 to 20 , with a mean of 12.03 .

Table 1

\begin{tabular}{ccccc}
\hline & \multicolumn{2}{c}{ Subscale Means and Standard Deviations } & Mean & Standard Deviation \\
\hline & & Range & 2.39 \\
\hline Organizational Role & $(1996)$ & $8-19$ & 12.72 & 1.95 \\
Orientation & $(2006)$ & $11-17$ & 13.88 & 5.96 \\
Professional Role & $(1996)$ & $5-46$ & 14.73 & 2.46 \\
Orientation & $(2006)$ & $10-20$ & 14.57 & 3.46 \\
Locus of & $(1996)$ & $5-20$ & 12.03 & 3.94 \\
Control & $(2006)$ & $4-18$ & 12.46 & 11.98 \\
Role Conflict & $(1996)$ & $21-72$ & 52.36 & 18.97 \\
& $(2006)$ & $22-93$ & 48.64 & 9.39 \\
Role Ambiguity & $(1996)$ & $23-64$ & 45.39 & 17.08 \\
& $(2006)$ & $18-89$ & 41.94 & 8.67 \\
Organizational & $(1996)$ & $29-69$ & 51.04 & 8.15 \\
Commitment & $(2006)$ & $28-64$ & 51.27 & 7.21 \\
Life Satisfaction & $(1996)$ & $56-109$ & 67.83 & 5.75 \\
\hline
\end{tabular}

(1996) $\mathrm{N}=55$

(2006) $\mathrm{N}=36$

Zero-order correlation coefficients for the personal attributes Organizational Role Orientation, Professional Role Orientation and Locus of Control with Organizational Commitment and Life Satisfaction are presented in Table 2. Only one significant correlation was found between these variables. Locus of Control was significantly correlated with Organizational Commitment ( $\mathrm{p}<.05)$. Specifically, women with greater internality of locus of control were more committed to their organizations. 
Table 2

Zero-order Correlations between Personal and Work-related Variables And Organizational Commitment and Life Satisfaction (1996)

\begin{tabular}{lcc}
\hline & $\begin{array}{c}\text { Organizational } \\
\text { Commitment }\end{array}$ & $\begin{array}{c}\text { Life } \\
\text { Satisfaction }\end{array}$ \\
\hline Locus of Control & $-.430^{*}$ & .051 \\
Organizational Role Orientation & -.032 & -.196 \\
Professional Role Orientation & .017 & -.122 \\
Role Conflict & $-.367 * *$ & .115 \\
Role Ambiguity & $-.418^{*}$ & .122 \\
\hline$* p<.05 * * p<.01$ & &
\end{tabular}

\section{Work-Related Attributes}

Means, ranges and standard deviations for the work-related variables of Role Conflict and Role Ambiguity are presented in Table 1. The scores for Role Conflict ranged from 21 to 72, with a mean of 52.36. Role Ambiguity scores ranged from 23 to 64 , with a mean of 45.39 .

Zero-order correlation coefficients for Role Conflict and Role Ambiguity with Organizational Commitment and Life Satisfaction are presented in Table 2. Role Conflict correlated significantly with Organizational Commitment $(\mathrm{p}<.01)$, as did Role Ambiguity $(\mathrm{p}<.05)$. Higher levels of conflict and ambiguity were related to lower levels of commitment. No significant correlations were found between the work-related variables and life satisfaction.

\section{Regression Analysis}

Included in Table 3 are the results of a regression analysis where significant zero-order correlations were used to identify independent variables that are associated with organizational commitment. As can be seen from Table 3, none of the independent variables made significant contributions to the regression model. However, the overall model was significant at the .031 level. (Model $\mathrm{R}^{2}=.294$; Overall $\left.\mathrm{F}=3.464\right)$. A step wise regression revealed Role Conflict as being the only variable making a significant contribution to the model (Model $\mathrm{R}^{2}=.307 ; \mathrm{F}=24.343$; $\mathrm{p}<.000)$.

Table 3

\section{Regression Analysis for Organizational Commitment (1996)}

\begin{tabular}{lllll}
\hline Variable & $\boldsymbol{B}$ & $\boldsymbol{S E} \boldsymbol{B}$ & $\boldsymbol{t}$ & $\boldsymbol{p}$ \\
\hline Role Ambiguity & -.169 & .213 & -.794 & .435 \\
Role Conflict & -.118 & .158 & -.743 & .464 \\
Locus of Control & -.713 & .413 & 1.726 & .097 \\
\hline Note: $R^{2}=.294($ A & . & &
\end{tabular}

Note: $R^{2}=.294$ (Adjusted $R^{2}=.209$ ). Overall $F=3.464 ; p<.031$

SAMPLE 2 (2006)

\section{Personal Attributes}

Means, ranges and standard deviations for all measured attributes may be found in Table 1. In this sample, Organizational Role Orientation scores ranged from 11 to 17, with a mean of 13.88. The mean score for Professional Role Orientation was 14.57, with scores ranging from 10 to 20. Scores on the Rotter Internal-External Locus of Control Scale ranged from 4 to 18 , with a mean of 12.46 . 
Zero-order correlation coefficients for the personal attributes Organizational Role Orientation, Professional Role Orientation and Locus of Control with Organizational Commitment and Life Satisfaction are presented in Table 4. Only one significant correlation was found between these variables. Professional Role Orientation was significantly correlated with Life Satisfaction $(\mathrm{p}<.05)$. Specifically, women who identified more strongly with their professionals were more satisfied with their lives.

Table 4

Zero-order Correlations between Personal and Work-related Variables And Organizational Commitment and Life Satisfaction (2006)

\begin{tabular}{lcc}
\hline & $\begin{array}{c}\text { Organizational } \\
\text { Commitment }\end{array}$ & $\begin{array}{c}\text { Life } \\
\text { Satisfaction }\end{array}$ \\
\hline Locus of Control & -.269 & -.152 \\
Organizational Role Orientation & .177 & .110 \\
Professional Role Orientation & .217 & $.377^{*}$ \\
Role Conflict & $-.651^{* *}$ & -.003 \\
Role Ambiguity & $-.640^{* *}$ & .074 \\
\hline
\end{tabular}

\section{Work-Related Attributes}

Means, ranges and standard deviations for the work-related variables of Role Conflict and Role Ambiguity are presented in Table 1. The scores for Role Conflict ranged from 22 to 93, with a mean of 48.64. Role Ambiguity scores ranged from 18 to 89 , with a mean of 41.94 .

Zero-order correlation coefficients for Role Conflict and Role Ambiguity with Organizational Commitment and Life Satisfaction are presented in Table 2. Role Conflict correlated significantly with Organizational Commitment $(\mathrm{p}<.01)$, as did Role Ambiguity $(\mathrm{p}<.01)$. Higher levels of conflict and ambiguity were related to lower levels of commitment. No significant correlations were found between the work-related variables and life satisfaction.

\section{Regression Analysis}

Included in Table 5 are the results of a regression analysis where significant zero-order correlations were used to identify independent variables that are associated with organizational commitment. As can be seen from Table 5, none of the independent variables made significant contributions to the regression model. However, the overall model was significant at the .001 level. (Model $\mathrm{R}^{2}=.464$; Overall $\mathrm{F}=12.773$ ). A step wise regression revealed Role Conflict as being the only variable making a significant contribution to the model (Model $\mathrm{R}^{2}=.457$; $\mathrm{F}=25.263 ; \mathrm{p}<.000$ ). A regression of Professional Role Orientation on Life Satisfaction was not necessary because Table 3 revealed only Professional Role Orientation as being associated with Life Satisfaction.

Table 5

\section{Regression Analysis for Organizational Commitment (2006)}

\begin{tabular}{lclcc}
\hline Variable & $\boldsymbol{B}$ & $\boldsymbol{S E} \boldsymbol{B}$ & $\boldsymbol{t}$ & $\boldsymbol{p}$ \\
Role Ambiguity & -.118 & .151 & -.782 & .441 \\
Role Conflict & -.197 & .140 & -1.412 & .169 \\
\hline
\end{tabular}

Note: $R^{2}=.464$ (Adjusted $R^{2}=.432$ ). Overall $F=12.773 ; p<. .001$ 


\section{DISCUSSION}

The results of this study indicate partial support for the hypotheses, which had been based on the results of a similar survey of U.S. women in higher education (Blackhurst, Brandt \& Kalinowski, 1998). Specifically, it was expected that the personal attribute of organizational role orientation would correlate positively with organizational commitment. This relationship was not found in either of the samples in the present study. No significant correlation was found between organizational role orientation and organizational commitment. This may be a function of the wording of the questions in the Role Orientation Scale in combination with an important difference between the samples of women in higher education surveyed in this study and those in the Blackhurst, Brandt, and Kalinowski (1998) study. The items on the Role Orientation Scale measuring organizational role orientation refer specifically to the importance of having an administrative role within the university. For example, one item reads: "Having a job which permits me to take on progressively more administrative responsibility is important to me." Given that the sample in the Blackhurst, Brandt, and Kalinowski (1998) study was comprised of Student Affairs administrators, it is not surprising that one would find higher levels of organizational role orientation than in the Slovak samples which included women having variety of roles in higher education. It may also be the case that the Slovak university has experienced a transition similar to what has occurred in Bulgaria in the post-communist period. Slantcheva (2003) reports that the various units within Bulgarian universities tend to work in isolation from one another, resulting in little university-wide cooperation. One would expect low levels of identification with one's organization under such conditions.

A second hypothesis in this study, predicting a negative correlation between professional role orientation and life satisfaction, was not supported. In fact, in the 2006 Slovak sample, a significant positive correlation was found between these variables. Women in the 2006 sample identified with their professions and this was related to higher levels of life satisfaction. This was not the case for the 1996 Slovak sample. This difference between samples may be explained by a difference in the extent to which research is a part of the work responsibilities of these women. The items on the Role Orientation Scale measuring Professional Role Orientation are focused on the importance of doing research and contributing to the body of knowledge within their professions. Demographic information from the Slovak samples indicates that the percentage of work responsibilities involving research in the 2006 sample was nearly twice what was reported in 1996. This may be idiosyncratic to these particular samples or it may represent a pattern in higher education that had been observed in post-Soviet Russia. Smolentseva (2003) observed that during the last 10 to 15 years researchers formerly employed in state-sponsored research institutes have transitioned into higher education because of higher pay and better support for research. This has resulted in a more research-oriented faculty in universities. It has also been noted that the research requirements for promotion within post-communist Russian (Smolentseva, 2003), Bulgarian (Slantcheva, 2003), and Polish (Kwiek, 2003) universities are greater now than ever before. There are many benefits, then, to identifying strongly with one's profession and the ability to make a significant research contribution to one's discipline. While the results of the present study are suggestive of a similar pattern in the Slovak Republic, further research is needed to specifically examine this question.

We expected that the work-related attributes of role conflict and role ambiguity would correlate negatively with organizational commitment and life satisfaction. A negative correlation was found between role conflict and role ambiguity and organizational commitment in both Slovak samples. Specifically, Slovak women who report high levels of role conflict and role ambiguity in the work setting have low levels of organizational commitment. In neither Slovak sample did we find a significant correlation between role conflict and role ambiguity and life satisfaction.

This observed relationship of role conflict and ambiguity with organizational commitment is consistent with findings on the relationship between these variables among U.S. women in higher education. It appears that, regardless of the larger social context, specific characteristics of the organization are important in predicting the commitment of women employees. When role expectations are in flux or unclear, commitment to the organization is reduced. Nowhere has this shift in role expectations been greater than in the Central and Eastern European university in the post-communist period (Smolentseva, 2003; Slantcheva, 2003; Kwiek, 2003). The data from the present study show a much stronger negative correlation between role ambiguity and organizational commitment in 
the 2006 sample than in 1996. This would suggest a similar pattern of shifting role expectations in the Slovak university as has been observed in the other post-communist countries.

In their 1998 study, Blackhurst, Brandt, and Kalinowski discuss several sources of role conflict for women in higher education. These include working as women in an environment defined by masculine values, the need for women to balance family and work responsibilities and inequities in the workloads of female and male employees. These sources of role conflict may be similar for the Slovak women in higher education surveyed in the present study. Under communism, equal participation by women across occupations was a goal. In the public universities of Central and Eastern Europe, while women were employed at rates equivalent to those of men, their status within the university was not on par with their male colleagues. In Poland, women dominate the lowest ranks within the university with very few promoted to the highest levels (Kwiek, 2003). Kwiek notes that the university reflects a traditional division of gender roles similar to that found within many Polish families. A similar trend has been observed in the Bulgarian university (Slantcheva, 2003). It appears likely, then, that women in the Slovak Republic may also experience one of the sources of role conflict, a male-defined work environment, outlined by Blackhurst, Brandt, and Kalinowski (1998).

Finding and maintaining a balance between work and family roles and responsibilities is another potential source of role conflict that has been observed in other post-communist Eastern European countries. The experiences of women in East Germany during and after the transition from a socialist state to a market-economy democracy were described by van Hoven (2002). It was noted that a result of this transition for women was the loss of socialist services that supported the family. Now issues related to child care and so forth became private problems for women and their families. That this would increase tension between work and family roles is not difficult to imagine. In the current study of Slovak women in higher education, the negative correlations between role conflict and organizational commitment were much higher in the 2006 sample than in 1996. One would expect this if the personal sequelae of the transition away from a communist state are comparable in the Slovak Republic to what was observed in East Germany.

Finally, we had predicted a positive correlation between life satisfaction and internal locus of control. This was not found in either the 1996 or 2006 Slovak samples. That this relationship was found in an earlier U.S. sample but not in the Slovak samples is not surprising. The values that define a culture influence the development of certain personality characteristics. Mueller and Thomas (2001) found that an internal locus of control is much more likely to develop in those who live in cultures which value individualism and less likely to occur in more collectivist cultures. The women surveyed in Slovakia in both 1996 and 2006 would have come of age at a time when communism was still in place. Internality, a highly individualized trait, would not be an important value for them and thus not an important contributor to life satisfaction.

While the results of this study were based on two data points with 10 year intervals to clarify the relationships between several work related and personal variables with organizational commitment and life satisfaction, the samples are not matched. Accordingly, we cannot make any definitive statements regarding whether the relationships found are based on changes within individuals. However, the fact that the relationships found were supported, in general, in both Slovak samples as well as the US would appear to suggest that there may be some common factors that correlate with organizational commitment. The sample sizes for both $1996(\mathrm{~N}=55)$ and $2006(\mathrm{~N}=36)$ were not as large as we would have liked, and while small sample sizes can lead to unstable beta estimates, we are again encouraged by the fact that work-related predictors of organizational commitment appear to be supported across all three samples (including the 1996 US sample).

We cannot assess the degree to which the translation of our instrument into the Slovak language affects the interpretation of items. We found a very strong correlation between role ambiguity and role conflict in both the 1996 and 2006 samples. This resulted in neither ambiguity nor conflict having significant B's in the full model regression analysis. A stepwise regression resulted in conflict predicting a significant proportion of the variance in commitment. The proportion of variance predicted by the stepwise model was larger than the full model and accordingly more parsimonious. However, we are concerned that the translation and subsequent interpretation for these scales appear to be so similar. 
Finally, Mitter (2003) and Grunberg (2001) have pointed out the criticality of taking into account regional specificities or the extent to which transformation processes in Central Europe are marked by diversity. We therefore are cautious regarding the generalizability of our results to other regions of Europe as well as the extent to which Western standards can be applied to countries experiencing dramatic changes to their economies. However, despite these limitations we have revealed several variables that appear to have common relationships particularly with respect to organizational commitment.

\section{ACKNOWLEDGEMENTS}

This research was initiated by Dr. Joanne E. Brandt who passed away in August, 2007. This work is dedicated to her memory.

\section{REFERENCES}

1. Blackhurst, A., Brandt, J., \& Kalinowski, J. (1998). Effects of personal and work-related attributes on the organizational commitment and life satisfaction of women student affairs administrators. NASPA Journal, Winter 35, 86-99.

2. Goodman, S.H. (1987). Convergent validity of five locus of control scales. Educational and Psychological Measurement, 47, 743-747.

3. Grunberg, L., (2005). Access to gender-sensitive higher education in Eastern and central Europe. European Education, 36, 54-69.

4. Kwiek, M., (2003). Academe in transition: Transformations in the Polish academic profession. Higher education, 45, 455-476.

5. Loscocco, K.A., \& Roschelle, A.R. (1991). Influences on the quality of work and nonwork life: Two decades in review. Journal of Vocational Behavior, 39, 182-225.

6. Mitter, W., (2003). A decade of transformation: Educational policies in central and Eastern Europe. International Review of Education, 49, 75-96.

7. Mueller, S. L., \& Thomas, A.S. (2001). Culture and entrepreneurial potential: A nine country study of locus of control and innovativeness. Journal of Business Venturing, 16(1), 51-75.

8. Murphy, C.A., Owen, S.V., \& Gable, R.K. (1988). Causes and consequences of role stress among higher education administrators. Paper presented at the annual meeting of the American Educational Research Association, New Orleans, LA.

9. Neugarten, B.L., Havighurst, R.J., \& Tobin, S.S., (1961). The measurement of life satisfaction. Journal of Gerontology, 16, 134-143.

10. Rotter, J.B., (1966). Generalized expectancies for internal versus external control of reinforcement. Psychological Monographs: General and Applied, 80(1).

11. Smolentseva, A., (2003). Challenges to the Russian academic profession. Higher education, 45, 391-424.

12. Slantcheva, S., (2003). The Bulgarian academic profession in transition. Higher education, 45, 425-454.

13. Steward, R. J., Patterson, B.T., Morales, P., Bartell, P., Dinas, P., \& Powers, R. (1995). Women in higher education: Does interpersonal style matter? NASPA,Journal, 33, 45-53.

14. van Hoven, B., (2002). Experiencing democracy: Women in rural East Germany. Social Politics, 9, 444470 .

15. Ward, L, (1995). Role stress and propensity to leave among new student affairs professionals. NASPA Journal, 33, 35-44.

16. Zerga, W.D., Jr., (1976). Stability and concurrent validity of the Rotter Internal-External Locus of Control Scale. Educational and Psychological Measurement, 36, 473-475. 